\title{
EPSP-IPSP Interactions in Cat Visual Cortex Studied with in vivo Whole-Cell Patch Recording
}

\author{
David Ferster and Bharathi Jagadeesh \\ Department of Neurobiology and Physiology, Northwestern University, Evanston, Illinois 60208
}

\begin{abstract}
Postsynaptic inhibition can operate by two distinct mechanisms: (1) membrane hyperpolarization and (2) shunting of excitatory postsynaptic currents. The arithmetic operations-either addition or multiplication-that synapses are able to perform during neuronal computations are determined by which of these two inhibitory mechanisms predominates. Hyperpolarizing IPSPs interact linearly with EPSPS; their negative and positive synaptic currents sum to produce a net change in membrane potential (Eccles, 1961). Shunting synapses interact nonlinearly with EPSPs; the shuntinduced increase in membrane conductance directly reduces the amplitude of EPSPs by a constant multiplicative factor (Fatt and Katz, 1953; Blomfield, 1974). This property of shunting inhibition has provided the basis for models of synaptic interaction in which shunting inhibition acts as an ANDNOT gate for excitatory inputs (Torre and Poggio, 1978; Koch et al., 1983).

Using an in vivo variant of the whole-cell patch technique (Blanton et al., 1989), we have examined the effect of visually evoked inhibition on the size of EPSPs in cortical simple cells and found that the predominant inhibitory mechanism is hyperpolarization. We conclude that these inhibitory synapses operate primarily in the linear mode.
\end{abstract}

The activity of a neuron depends not only on the activity of its presynaptic excitatory and inhibitory inputs, but also on the manner in which those inputs are integrated by the cell. Specifically, the linearity or nonlinearity of the interactions between EPSPS and IPSPs profoundly affects the operations that neurons are able to perform on the information that they receive, process, and transmit. The importance of this synaptic arithmetic is illustrated in models of neuronal computation. Many connectionist neural network models, for example, are based on the assumption that IPSPs interact linearly with EPSPs (Rumelhart and McClelland, 1986). In these models, the net input to any given "neural" unit is the weighted sum of the activity of all its "presynaptic" units, with positive activity representing excitation and negative activity representing inhibition.

Nonlinear interactions between EPSPs and IPSPs have been used to model a "synaptic veto" mechanism or AND-NOT gate

Received Aug. 8, 1991; revised Oct. 24, 1991; accepted Oct. 31, 1991

We thank Steven Glaum and Lawrence Pinto for their generous advice on the whole-cell patch technique. Mark Segraves, Eugene Silinsky, and Michael Stryker commented on the manuscript. This work was supported by the National Fye Institute (Grant R01 EY04726) and the McKnight Endowment Fund for Neuroscience.

Correspondence should be addressed to David Ferster, Department of Neurobiology and Physiology, Northwestern University, Evanston, IL 60208.

Copyright (C) 1992 Society for Neuroscience $0270-6474 / 92 / 121262-13 \$ 05.00 / 0$
(Torre and Poggio, 1978; Koch ct al., 1983). Each active inhibitory synapse attenuates or divides the amplitude of simultaneously evoked EPSPs by a constant factor. The AND-NOT gate has been used to model receptive field properties, such as direction selectivity and disparity sensitivity in neurons of the retina and visual cortex (Torre and Poggio, 1978; Ferster, 1981; Koch et al., 1982; Koch and Poggio, 1985).

The physiological mechanism that underlies linear IPSP-EPSP interactions is conventional hyperpolarizing inhibition. When a hyperpolarizing synapse is activated, negative current enters the cell, driving the membrane potential away from threshold, thereby reducing the neuron's excitability. The interaction with EPSPs is largely linear since the currents injected by both excitatory and inhibitory synapses sum on the membrane capacitance (Eccles, 1961).

The physiological mechanism that underlies nonlinear IPSPEPSP interactions is shunting inhibition. When a shunting synapse is activated, ion channels open in the postsynaptic membrane exactly as they do with hyperpolarizing inhibition. Shunting synapses, however, need not, by themselves, admit hyperpolarizing current into the cell. Instead, the opening of the synaptic channels causes a conductance change that is large enough to shunt excitatory postsynaptic currents (EPSCs) generated at nearby synapses. A fraction of any excitatory current passing by the shunting synapse will leak out of the open inhibitory channels, reducing the size of the EPSPs gencratcd by the excitatory current.

Single inhibitory synapses may have both shunting and hyperpolarizing effects. The magnitude of the hyperpolarizing effect depends on the size of the driving force on the ions to which the inhibitory channels are permeable. The magnitude of the shunting effect depends primarily on the size of the conductance of the active synapse.

Shunting and hyperpolarizing inhibition differ not only in their linearity, but also in the duration and spatial spread of their effectiveness. Hyperpolarizing inhibition lasts as long as the IPSP lasts, which can be tens of milliseconds, depending on the time constant of the cell. Shunting effects, however, last only as long as the postsynaptic ion channels remain open, which is on the order of a few milliseconds for receptors directly linked to ion channels. Hyperpolarizing IPSPs also have a much broader spatial spread than shunting inhibition. Wherever a hyperpolarizing IPSP is generated, it has a direct effect on the membrane potential of the soma, and therefore on neuronal excitability. Shunting inhibition, in contrast, acts only locally, attenuating only those EPSPs generated nearby in the dendritic tree. Shunting inhibition can therefore selectively antagonize the effects of EPSPs generated at specific times and within specific regions of the dendritic tree. The result is a neuron capable of performing multiple independent calculations in different parts of its den- 
dritic tree (Koch and Poggio, 1985), making shunting an attractive mechanism for modeling the complex responses of neurons.

Hyperpolarizing inhibition is a common feature among neurons of the mammalian CNS. Shunting inhibition is experimentally more difficult to detect, and the extent to which it occurs is still unclear. One way to test for the presence of shunting inhibition is to search for the changes in input resistance that should accompany the activation of shunting synapses (Douglas et al., 1988; Pei et al., 1991). This method might fail to detect shunts if they were located on spines or in electrically remote regions of the dendritic tree. While models of the electrical properties of cortical neurons suggest that no regions of the dendrites are electrotonically remote from the soma (Koch ct al., 1990), this question remains to be tested experimentally in cortical cells in vivo.

A more direct method of measuring the shunting induced by inhibitory synapses was used in the crayfish muscle fiber by Fatt and Katz (1953). The crayfish muscle is innervated by two motoneurons, one of which is excitatory and one inhibitory. Stimulating the excitatory motoneuron evoked a large EPSP; stimulating the inhibitory motoneuron by itself evoked only a small change in membrane potential. When the excitatory and inhibitory motoneurons were stimulated simultaneously, however, the amplitude of EPSP was significantly reduced. With this result, Fatt and Katz demonstrated the physiologically relevant effort of shunting inhibition, its reduction of the effectiveness of the EPSP. A similar method was used to search for shunting in neurons of the guinea pig PNS (Edwards et al., 1976).

We have adapted the Fatt and Katz experiment to test for the presence of visually cvokcd shunting inhibition in the mammalian cortex. For the EPSP generated by stimulation of the crayfish excitatory motoneuron, we have substituted a test EPSP generated by electrical stimulation of the LGN. For the electrical stimulation of the inhibitory motoneuron, we have substituted visual stimulation. Any shunting inhibitory synapses activated by the visual stimulus should significantly reduce the amplitude of the test EPSP. Since the test EPSP arises from excitatory synapses located throughout the dendritic tree, it acts as a reliable probe for shunting synapses located anywhere within the dendritic tree.

\section{Materials and Methods}

Animal preparation. Experiments were performed on young adult female cats, $2-3 \mathrm{~kg}$ in weight. Anesthesia was induced with a mixture of kctamine hydrochloride $(30 \mathrm{mg} / \mathrm{kg})$ and acepromazine $(0.3 \mathrm{mg} / \mathrm{kg})$ given intramuscularly. A cannula was then inserted into a femoral vein, and anesthesia was maintained for the rest of the experiment with an intravenous infusion of sodium thiopental $(30 \mathrm{mg} / \mathrm{kg}$ initial dose, $1-2 \mathrm{mg} /$ $\mathrm{kg} / \mathrm{hr}$ maintenance dose). A second venous cannula was inserted for infusion of a muscle relaxant, and a tracheal cannula was inserted for artincial respiration. The animal was then placed in a stereotaxic head holder with the thorax suspended from a clamp on the cervical vertebrae. A pneumothorax was performed to minimize respiratory-induced movements of the brain.

To minimize motion of the eyes, paralysis was induced with pancuronium bromide $(0.2 \mathrm{mg} / \mathrm{kg}$ initial dose, $0.2 \mathrm{mg} / \mathrm{kg} / \mathrm{hr}$ maintenance dose) after surgery was completed. The cat was then artificially respirated throughout the experiment at a rate sufficient to maintain peak expired $\mathrm{CO}_{2}$ at $3.5-4 \%$. Body temperature was maintained at $38.5^{\circ} \mathrm{C}$. Several measures were taken to ensure that the animal was properly anesthetized during paralysis. (1) Paralysis was not begun until all major surgery was completed and a stable state of anesthesia was clearly maintained by the pentathol infusion. (2) Doses of pentathol in addition to the steady infusion were given if indicated by a change in heart rate. To test the pentathol dosage, two animals have been maintained for over $10 \mathrm{hr}$

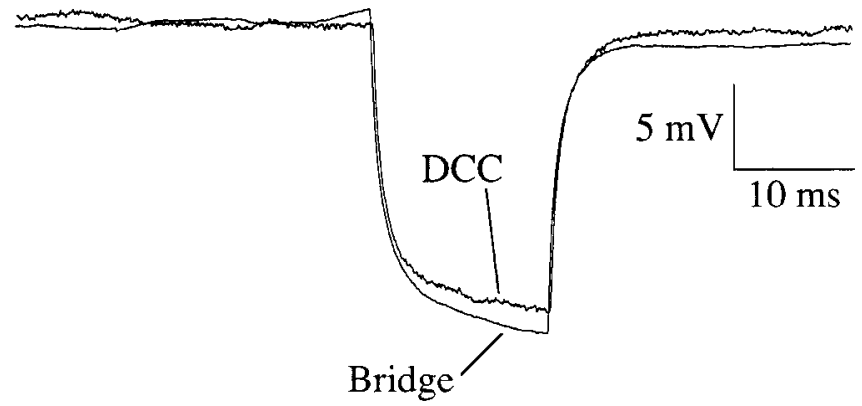

Figure 1. The response of a cortical cell to a 100 pA current pulse. Two traces are superimposed, one recorded in conventional bridge mode (Bridge) with resistance compensation set to $0 \mathrm{M} \Omega$, the other in discontinuous current clamp mode $(D C C)$. The resting potential of the cell was $-65 \mathrm{mV}$. The neuron's input resistance was $180 \mathrm{M} \Omega$, and the electrode resistance, $12 \mathrm{M} \Omega$.

without paralytic; the dose of pentathol normally used in our experiments was sufficient to ensure a proper level of anesthesia in these animals.

Intracellular recording. Intracellular current-clamp records were obtained using an in vivo variation of the whole-cell patch method (Hamill et al., 1981) developed by Blanton et al. (1989) for use in neuronal tissue slices. Patch electrodes were made from fiber-containing borosilicate glass capillaries of $1.2 \mathrm{~mm}$ outer diameter and $0.9 \mathrm{~mm}$ inner diameter. They were pulled on a horizontal puller (Sutter Instruments) with a twostage pull. Resulting electrode tip sizes ranged from 1 to $1.5 \mu \mathrm{m}$. Compared to electrodes designed for in vitro use, our electrodes were given a long taper $(6-7 \mathrm{~mm})$ in order to minimize dimpling of the cortical surface. Resistances ranged from 5 to $12 \mathrm{M} \Omega$ when the electrodes were filled with a solution buffered to $\mathrm{pH} 7.4$ containing (in $\mathrm{mM}$ ) $\mathrm{K}^{+}$-gluconate, 135; HEPES, 5; $\mathrm{MgCl}_{2}$, 2; EGTA, $1.1 ; \mathrm{CaCl}_{2}$, 0.1; ATP, 3; GTP, 2; and rGMP, 0.02 (adjusted to $280 \mathrm{mOsm}$ ). In some cases, subsequent to being filled, the tapering part of the electrode was coated to within $1 \mathrm{~mm}$ of the tip with M-Coat acrylic coating (Measurements Group, Inc., Raleigh, NC) to reduce electrode capacitance.

Electrodes were introduced into the brain through a long, narrow craniotomy positioned over the lateral gyrus (Horsely-Clark coordinates: lateral 1 to lateral 3, AP 0 to AP -9). The dura over the cortex was reflected, while the pia and arachnoid were left intact. An electrode was positioned over the cortex using a hydraulic microdrive (Newport, Fountain Valley, CA). The craniotomy was then covered with warm agar (3\% in normal saline) to prevent drying of the cortical surface and to reduce vascular pulsations. After the agar solidified, the electrode was advanced slowly through the cortex. At the same time, a small amount of positive pressure (approximately $30 \mathrm{~mm} \mathrm{Hg}$ ) was maintained on the electrode. Electrode resistance was monitored by observing the change in voltage induced by a $20-30 \mathrm{msec}$ current pulse of $-100 \mathrm{pA}$, using an Axoclamp intracellular amplifier (Axon Instruments, Foster City, CA) in the bridge mode. An increase in resistance of 20-50 M $\Omega$ was taken as a sign that the electrode had encountered the membrane of a cell. At that point, the positive pressure was removed from the electrode, and slight suction was applied by mouth. In some cases, a gigaohm seal was obtained, as indicated by the response to the current pulse. Further brief pulses of negative pressure were then applied to break the seal. A successful recording was indicated by a sudden drop in seal resistance and the appearance of a resting potential, along with large synaptic potentials evoked by electrical stimulation of the LGN. After each attempt at obtaining a seal, the electrode was replaced. Successive electrode tracks were spaced approximately $1 / 2 \mathrm{~mm}$ apart on the cortical surface.

Intracellular potentials were recorded by computer at a sample rate of $4 \mathrm{kHz}$ for visually evoked responses and $15 \mathrm{kHz}$ for electrically evoked responses. Signals were low-pass filtered before digitization to prevent aliasing.

Resting potentials for 25 neurons obtained with the whole-cell patch method ranged from $-45 \mathrm{mV}$ to $-70 \mathrm{mV}$, with an average of $-60 \mathrm{mV}$. Cells were held for between 5 and $90 \mathrm{~min}$, with an average of $35 \mathrm{~min}$. The depth of the neurons from the cortical surface ranged from 100 to $900 \mu \mathrm{m}$. Cells were located in layers $1-5$, as indicated by their orthoand antidromic responses to electrical stimulation and by their receptive 


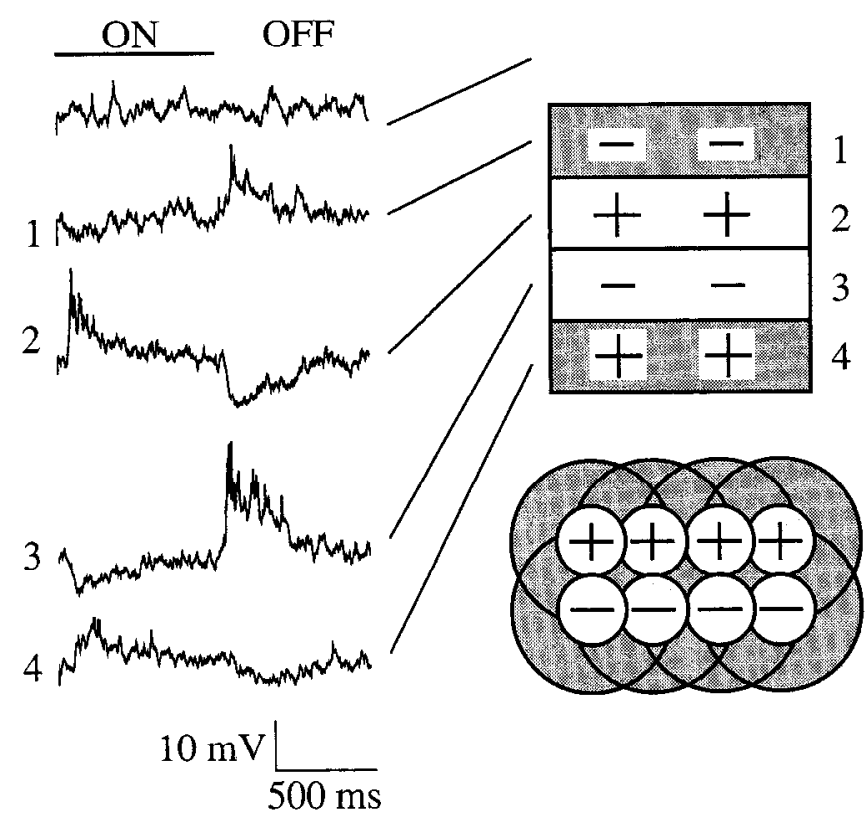

Figure 2. The response of a simple cell in layer 4 of area 17 to an optimally oriented bar of light flashed at five different positions in and around its receptive field. The horizontal har at the top of the traces indicates the time during which the stimulus bar was on. Each trace represents the average of the response to four separate presentations of the stimulus. The cell's resting potential was $-60 \mathrm{mV}$. The schematic diagram of the receptive field shown to the right of the traces (top) indicates for each trace the position of the bar relative to the four subregions of the receptive field. The bar was presented at several different positions within each subregion. The response shown for each subfield is the maximal one obtained within that subfield. The diagram at the lower right represents an arrangement of the receptive fields of relay cells in the LGN that, were they presynaptic to the simple cell, might account for the observed responses.

field properties (Ferster and Lindström, 1983). Of the 25 neurons from which whole-cell recordings were obtained, the test for shunting inhibition was performed on five simple cells from layer 4 and one complex cell from layer 3 . Only those cells will be considered in the results.

Input resistances varied from $50 \mathrm{M} \Omega$ to $200 \mathrm{M} \Omega$, as measured with a current pulse of $100 \mathrm{pA}$ passed through the recording electrode. An example of the response of the membrane potential to a test pulse is shown for a complex cell in Figure 1. Two traces are superimposed in the figure. One is the response to the test pulse recorded in the continuous current-clamp (bridge) mode, but with no compensation for electrode resistance. The second is the response recorded in the discontinuous current-clamp (switch-clamp) mode with a switching rate of $9 \mathrm{kHz}$. The switch-clamp record indicates that the cell had an input resistance of approximately $180 \mathrm{M} \Omega$. The difference in the two traces arises from the electrode resistance of approximately $15 \mathrm{M} \Omega$.

Visual stimulation. High-contrast moving and stationary bars of light were projected onto a tangent screen 57 inches away from the cat's eyes. Phenylephrine hydrochloride $(10 \%)$ was applied to the eyes to retract the nictitating membranes; atropine sulfate $(1 \%)$ was applied to dilate the pupils and paralyze accommodation. Contact lenses with 4-mmdiameter artificial pupils were inserted. The power of the contact lenses was chosen to focus the retina onto the tangent screen. All visual stimuli were presented monocularly to the dominant eye.

Electrical stimulation of the lateral geniculate nucleus. A stimulating electrode was placed in the LGN. This electrode was an etched, lacquercoated tungsten wire, with $200-500 \mu \mathrm{m}$ exposed at the tip. Its position was chosen in each experiment so that the receptive fields of neurons recorded from its tip were located on the tangent screen $2-3^{\circ}$ below and lateral to the projection of the area centralis. When the positions of the geniculate stimulating electrode and cortical recording electrode were properly matched within the receptive-field maps of the two structures, the thresholds of cortical field potentials evoked from the LGN were less than $100 \mu \mathrm{A}$ (200 $\mu \mathrm{sec}$ duration, electrode negative).

\section{Results}

Shunting inhibition attenuates the amplitude of EPSPs generated by simultaneously active excitatory synapses. We searched for such attenuation in simple cells by stimulating the LGN to produce a test EPSP, while monitoring changes in its amplitude induced by visual stimulation of the receptive field. Any decreases in the amplitude of the test EPSP systematically related to the visual stimulus might indicate that the visual stimulus had activated shunting inhibition.

\section{The response to visual stimulation}

In order to interpret changes in test EPSP size caused by the visual stimulus, it was necessary first to characterize the responses to visual stimulation alone. Sample records illustrating the structure of the visual receptive field of a simple cell in layer 4 are shown in Figures 2 and 3. This cell had a resting potential of $-60 \mathrm{mV}$ and input resistance of $200 \mathrm{M} \Omega$. The receptive field of this cell was divided into four subregions: two ON regions and two OFF regions. Flashing a bar of light of the preferred orientation in either ON region (Fig. 2, traces 2 and 4) evoked depolarization when the light came on and hyperpolarization when the light went off. Flashing the bar in either OFF region (Fig. 2, traces 1 and 3) evoked depolarization when the light went off and hyperpolarization when the light came on. Flashing the bar outside the receptive field (the unnumbered trace) produced no significant response.

The amplitudes of the intracellular responses evoked from subficlds 2 and 3 arc twice as large as those evoked from subfields 1 and 4, indicating that the two centrally located subfields (2 and 3) are about twice as responsive as the two peripherally located ones ( 1 and 4$)$. In addition, action potentials could be evoked only from regions 2 and 3. (This is evident in individual traces, though not in the averaged traces of Fig. 2.) Presumably, in extracellular records only regions 2 and 3 would have been detected. The subregions of simple receptive fields have been proposed to arise from presynaptic geniculate relay cells whose receptive fields are arranged in rows (Hubel and Wiesel, 1962; Chapman et al., 1991). According to the model, subregion 2 arises from a row of presynaptic on-center cells, and subregion 3 from a row of off-center cells, as shown in Figure 2, lower right. The weaker excitatory responses of region 1 could then be accounted for by the surrounds of the relay cells whose centers contributed to region 2. Similarly, region 4 results from the surrounds of relay cells underlying region 3 .

The response of the simple cell to a moving visual stimulus is presented in Figure 3 . When an appropriately oriented bar was swept across the receptive field (Fig. $3 A, B$ ), a series of depolarizations and hyperpolarizations occurred as the bar encountered each of the subfields in turn. The four phases of the response to downward motion represent (1) hyperpolarization as the bar enters OFF region 1, (2) depolarization as the bar enters ON region 2 and simultaneously leaves OFF region 1 , (3) hyperpolarization as the bar enters OFF region 3 and leaves $\mathrm{ON}$ region 2, and (4) depolarization as the bar enters $\mathrm{ON}$ region 4 and leaves OFF region 3 . The sequence is repeated in reverse order as the bar moves across the receptive field in the opposite direction (Fig. 3B).

Sweeping the bar across the receptive field in the nonpreferred orientation (Fig. $3 C, D$ ) evokes only a small depolarization, barely visible in the individual traces. This small depolarization can also be explained in terms of the input from the presynaptic 
A

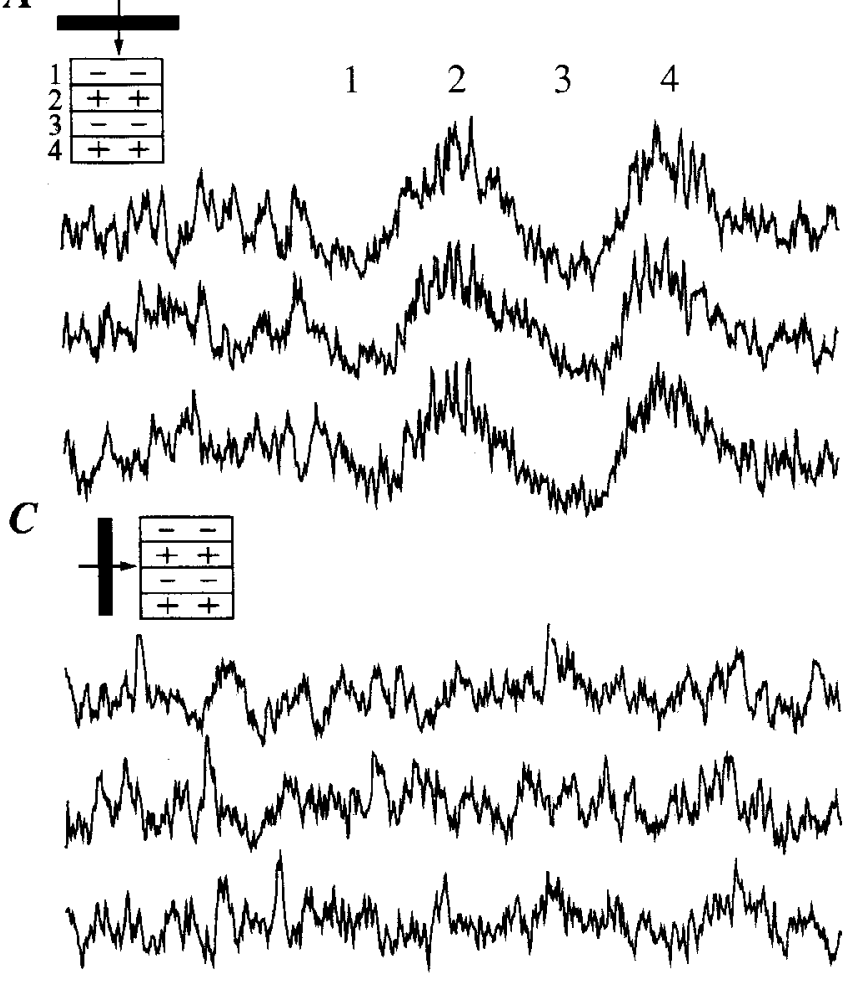

$\boldsymbol{B}$

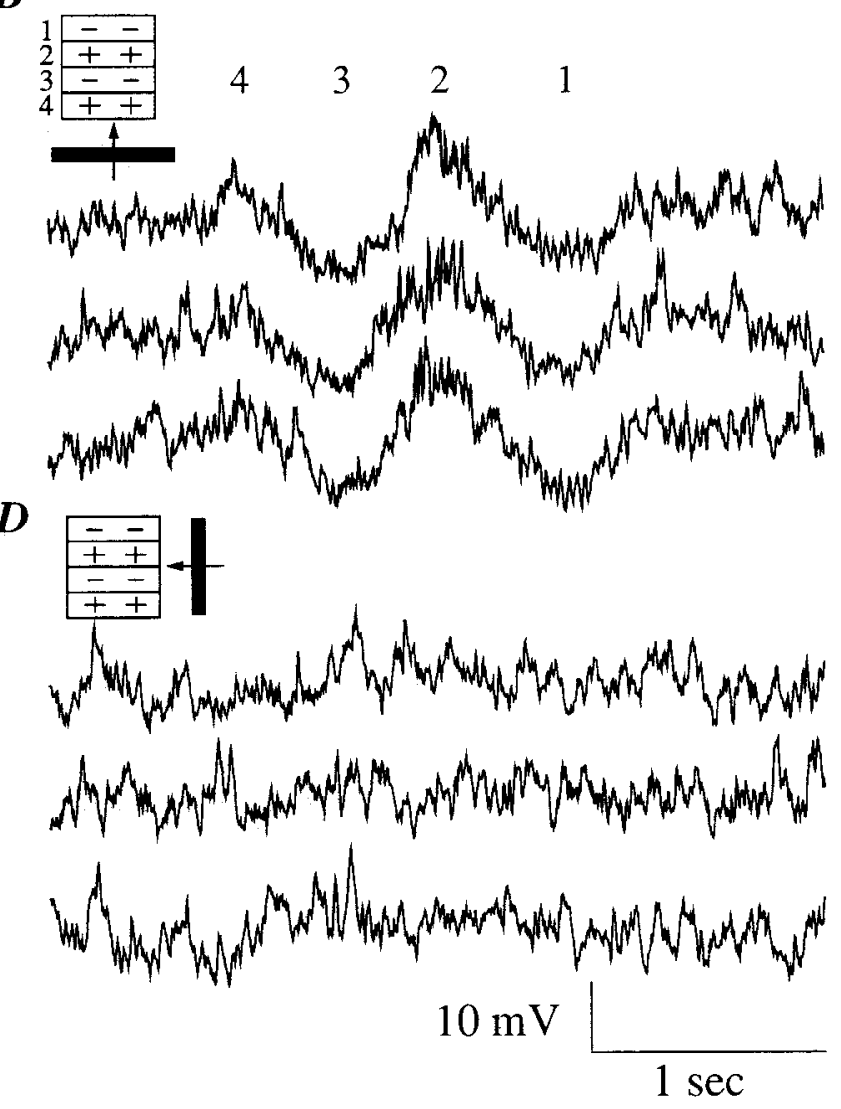

Figure 3. The response of the simple cell in Figure 2 to the bar being swept across its receptive field in four different directions, as indicated by the inset above each set of traces. The responses to three consecutive stimulus presentations are shown for each direction of motion. The numbers above the responses to the optimal stimulus orientations indicate the approximate times during which the visual stimulus had entered the regions of the receptive field in which the bar was flashed to obtain the five responses of Figure 2.

relay cells proposed in Hubel and Wiesel's (1962) model. The response is reduccd in size compared to the preferred response for two reasons. (1) The individual relay cells are activated sequentially, not simultaneously, as the bar is moved in the direction perpendicular to the rows of their receptive fields. (2) The bar simultaneously encounters the receptive field centers of both ON-center and OFF-center relay cells. The bright bar increases the activity of the ON-center cells, while it reduces the background activity of the OFF-center cells. The net effect is only a small depolarization in the simple cell.

\section{The effect of visual stimulation on test EPSP size}

Once the cell's response to visual stimulation alone was determined, electrical stimulation of the LGN was delivered together with visual stimulation. The electrical stimulus to the LGN evoked an EPSP in the cell (referred to as the test EPSP). A low frequency of electrical stimulation (approximately $1 \mathrm{~Hz}$ ) was used so that the cortical visual response would have time to recover from the disruption caused by one electrical stimulus before the next one was delivered. The exact frequency of electrical stimulation was chosen for each cell so as not to match the frequency of the sweep of the visual stimulus. The asynchronous presentation of electrical and visual stimuli meant that each successive electrical stimulus was delivered with the visual stimulus located at a slightly different position within the re- ceptive field. A diagram of the manner in which test EPSPs were evoked in the midst of the response to the visual stimulus is shown in Figure 4. In trial 1, the electrical stimulus was delivered as the bar entered the first subregion of the receptive field. The resulting test EPSP is highlighted by the small rectangle overlying the trace and is shown with an expanded time base in the box below the visual trace. In trial 2 , the electrical stimulus was delivered as the bar left the second subregion of the receptive field. In all, 200-300 electrical stimuli were applied in order to test the effects of the bar as it swept through each portion of the receptive field.

A series of 13 test EPSPs recorded from the cell in Figures 2-4 are superimposed in Figure $5 \mathrm{~A}$. In this cell, and in all of the simple cells studied, two major EPSP components are visible. The early component (labeled " 1 " in Fig. $5 \mathrm{~A}$ ) with a latency of $1.8 \mathrm{msec}$ reflects monosynaptic excitation from the relay cells of the LGN (Ferster and Lindström, 1983). The later component (labeled " 2 " in Fig. $5 A$ ) reflects excitation from corticogeniculatc cells of layer 6 that have been antidromically activated by the geniculate stimulus (Ferster and Lindström, 1985). A diagram of the circuit that mediates these two components of the EPSP is shown in Figure $5 B$. Although the two components of the EPSP have very different latencies, they are both mediated by monosynaptic connections. The long latency of the second component (3.6 msec) is caused by the slow conduction velocity of the antidromically activated corticogeniculate axons. Following 

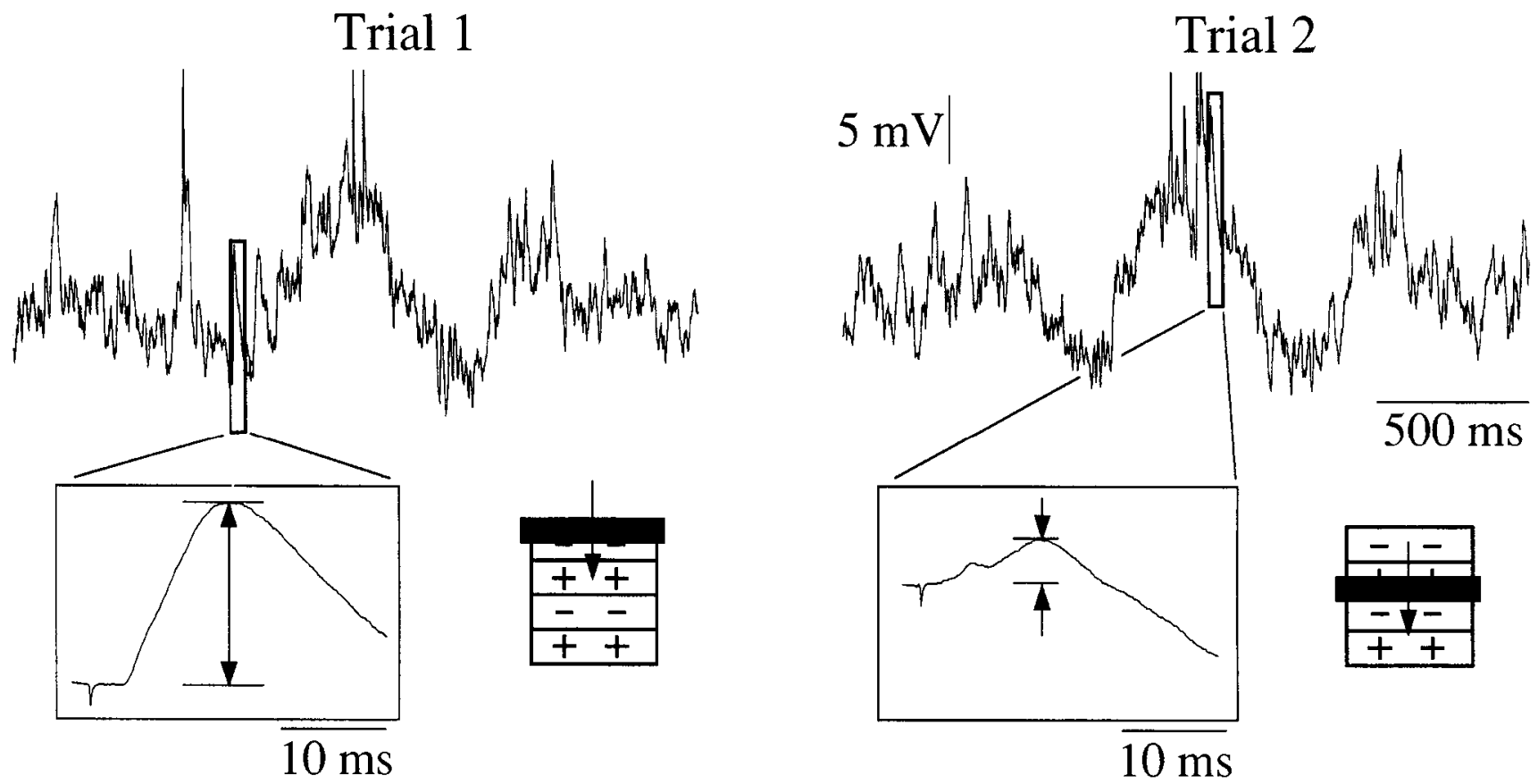

Figure 4. A schematic diagram of a test F.PSP evoked in the midst of the response to the visual stimulus for the cell illustrated in Figures 2 and 3. In Trial 1 , the electrical stimulus was delivered as the bar entered the first subregion of the receptive field. The response to the electrical stimulus is highlighted by the small rectangle overlying the trace, and is shown with an expanded time base in the box below. In Trial 2, the electrical stimulus was delivered as the bar left the second subregion of the receptive field.

the two EPSP components is a long-lasting IPSP, the beginning of which is visible at the end of the records (labeled " 3 " in Fig. $5 A)$.

The amplitude of the postsynaptic response to the electrical stimulus varies dramatically from trial to trial. The smallest of the responses contained in Figure $5 A$ are less than $20 \%$ of the size of the largest. Both components of the test EPSP vary in size; a reduction in one component is usually accompanied by a reduction in the other. To determine how variations in test EPSP amplitude are related to the visual stimulus, the test EPSP amplitude was plotted against the position within the receptive field at which the bar was located when each electrical stimulus was delivered (Fig. 6). The amplitude of the test EPSP was defined as the difference between the potential measured at point

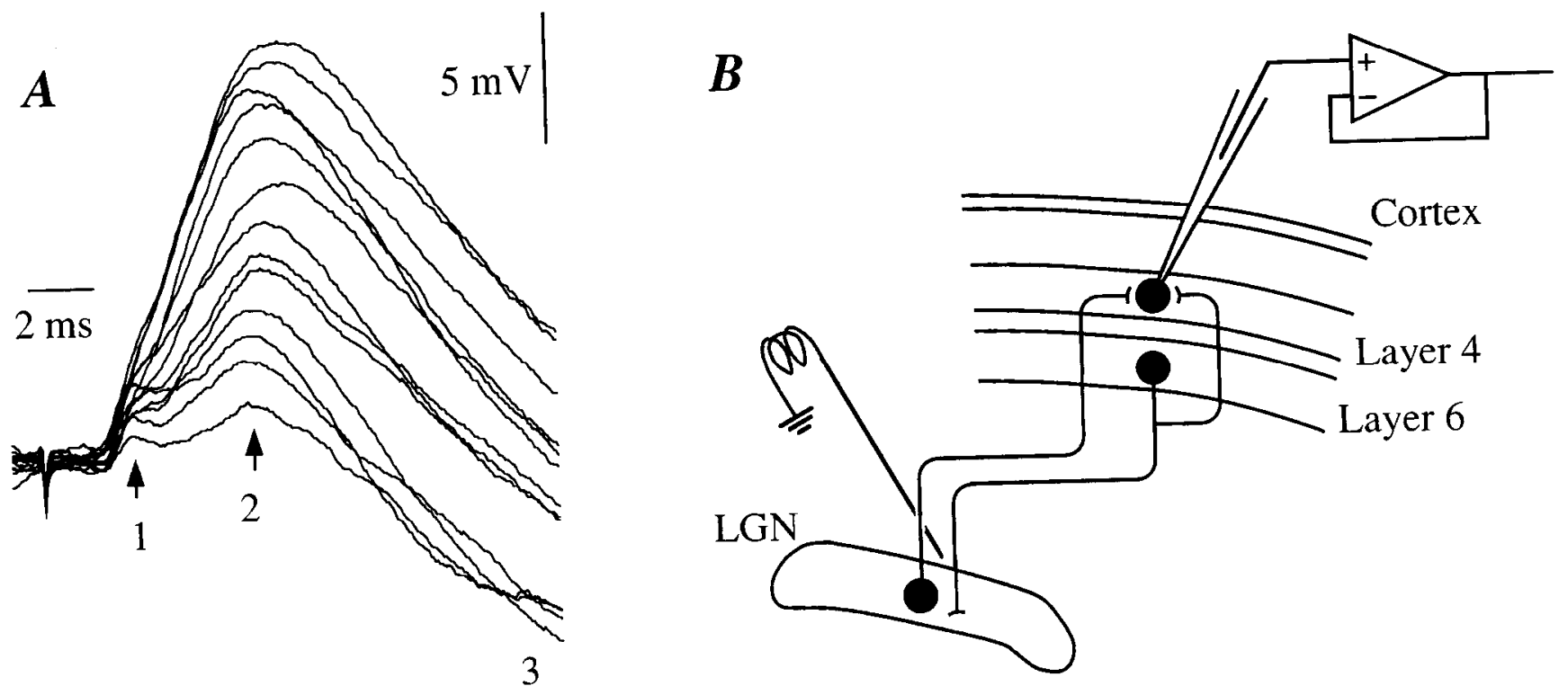

Figure 5. A, Test EPSPs generated in the simple cell of Figure 2 by electrical stimulation of the LGN. The three components of the response labeled $1-3$ correspond to $(l)$ a monosynaptic EPSP mediated by relay cells of the LGN, (2) a monosynaptic EPSP mediated by antidromic activation of layer 6 corticogeniculate neurons and their intracortical collaterals, and (3) the beginning of a disynaptic IPSP, which lasted for 200 msec and reached a peak amplitude of $15 \mathrm{mV}$. The records were made while an optimally oriented visual stimulus was moving back and forth across the receptive field. The traces have been shifted vertically by up to $10 \mathrm{mV}$ or more so that the 1 msec portion of each trace preceding the shock artifact is superimposed with the others. $B$, A schematic diagram indicating the position of the electrical stimulus and location of the axons stimulated by it. 


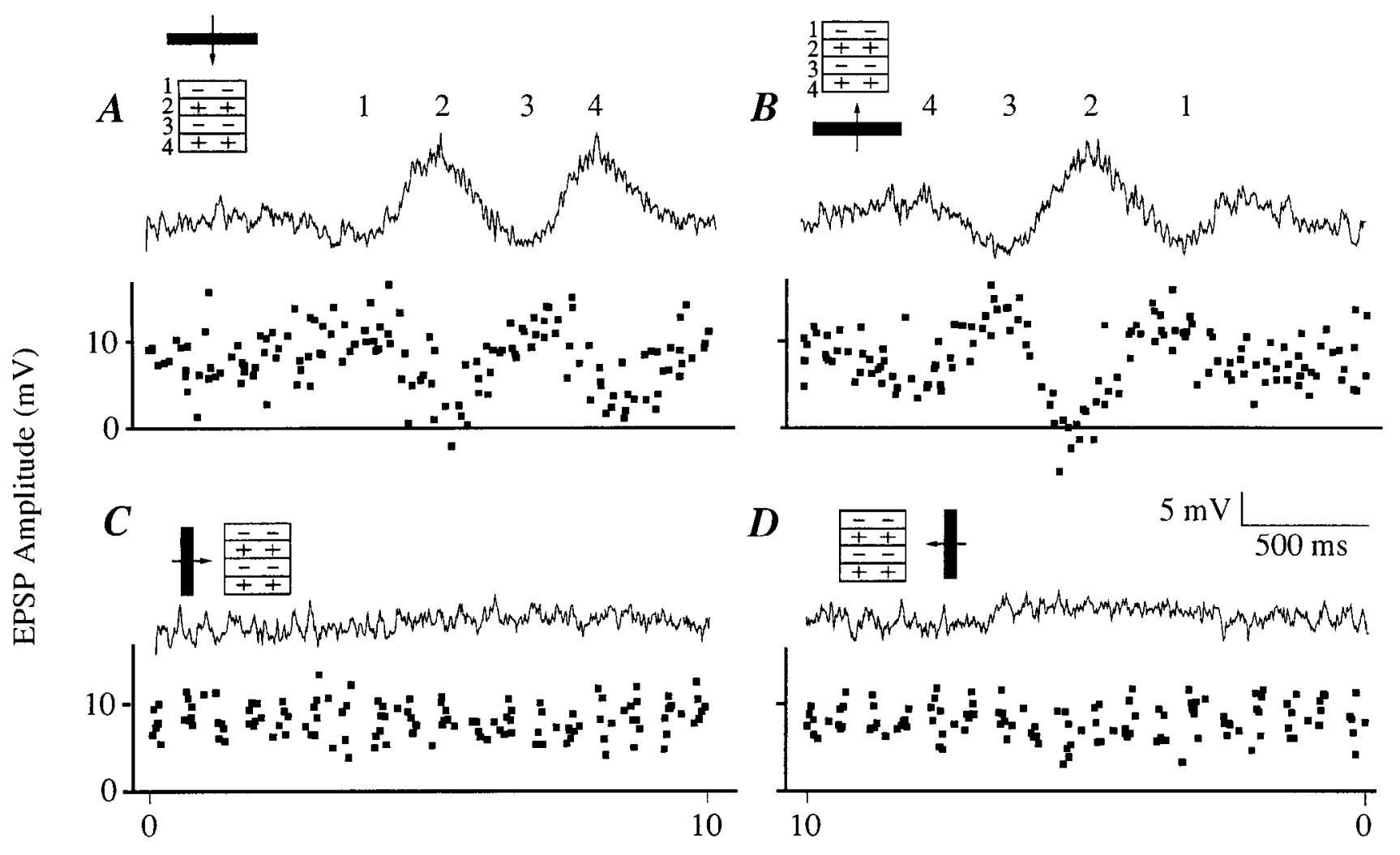

\section{Bar Position (deg)}

Figure 6. Four graphs of the amplitude of the test EPSP (measured at point 2 in Fig. 5 ) as a function of the position of the visual stimulus within the receptive field. The four different graphs correspond to four different directions of stimulus motion. Above each plot, a continuous trace shows the membrane potential changes evoked by the visual stimulus alone. Each of these traces is an average of four individual responses. The graphs and the continuous curve are plotted in register: for a given bar position, the instantaneous membrane potential in the absence of electrical traces stimulation is located directly above the corresponding test EPSP amplitude. During the recording of all traces in the figure, the cell was held hyperpolarized with $-120 \mathrm{pA}$ of current injected through the recording electrode. The current was applied to prevent the test stimulus from evoking action potentials that would obscure the peak of the response. The injected current hyperpolarized the membrane potential (measured at the beginning of each trace, with the visual stimulus outside the receptive field) from -60 to $-80 \mathrm{mV}$. The insets, and the numbers above the responses in $A$ and $B$, are identical to these in Figure 3.

" 2 " in Figure $5 A$ (near the peak of the second component) and the potential measured $1 \mathrm{msec}$ after the shock artifact. Traces in which action potentials occurred prior to the EPSP peak were excluded from the graphs because of the resulting distortion in EPSP shape. Four separate graphs are shown for four different directions of bar motion, which is indicated in the inset accompanying each graph. The continuous curve above each graph is the visually evoked membrane potential recorded in the absence of electrical stimulation. The graph and the continuous curve are plotted in register: for a given bar position, the instantaneous membrane potential in the absence of electrical stimulation is located directly above the corresponding test EPSP amplitude.

The graphs of Figure 6 show that the size of the test EPSP is strongly correlated with the position of the visual stimulus within the receptive field. With the bar at the preferred orientation (Fig. 6A,B), the test EPSP amplitude is consistently reduced by $80 \%$ or more when the bar enters the ON regions ( 2 and 4 ) of the receptive field. Conversely, the test EPSP size is increased slightly when the bar enters the OFF regions. Little significant change in test EPSP amplitude occurs when the bar passes through the receptive field in the nonpreferred orientation.

Part of the variation in test EPSP size visible in Figure 6 is unrelated to bar position: there is considerable scatter in the size of the test EPSP at any one bar position. Part of the scatter is attributable to normal variations in the size the test EPSP that occur even in the absence of visual stimulation. The test EPSP rides on top of spontaneous and visually evoked fluctuation in membrane potential which can distort the EPSP's shape. The distortion is large enough in some cases to make the smallest test EPSPs appear to have a slightly negative amplitude.

The effect of visual stimulation on the test EPSP is shown for a second simple cell in Figures 7 and 8 . Sample responses to the electrical stimulation are shown in Figure 7. For this cell, the size of the early component of the test EPSP (thin arrow in Fig. 7) is plotted against the position of the visual stimulus in Figure 8 . The organization of Figure 8 is similar to that of Figure 6 . The continuous traces show the averaged response of the membrane potential to the visual stimulus alone. Below each trace, the amplitude of the test EPSP, recorded while the visual stimulus swept across the receptive field, is plotted against the instantaneous position of the bar. The response to the moving bar and to a flashing bar (not shown) indicates that the receptive field of this cell had five subregions, three $O N$ regions alternating with two OFF regions. As in Figure 6, the visual stimulus evoked sequential depolarizations as the bar of preferred orientation entered an ON region or left an OFF region. Unlike the cell in Figure 6, a bar of the nonpreferred orientation evoked a significant depolarization in the cell of Figure 8 (though few action potentials). The response to the orthogonal orientation consists of a single wave of depolarization with a peak amplitude slightly 


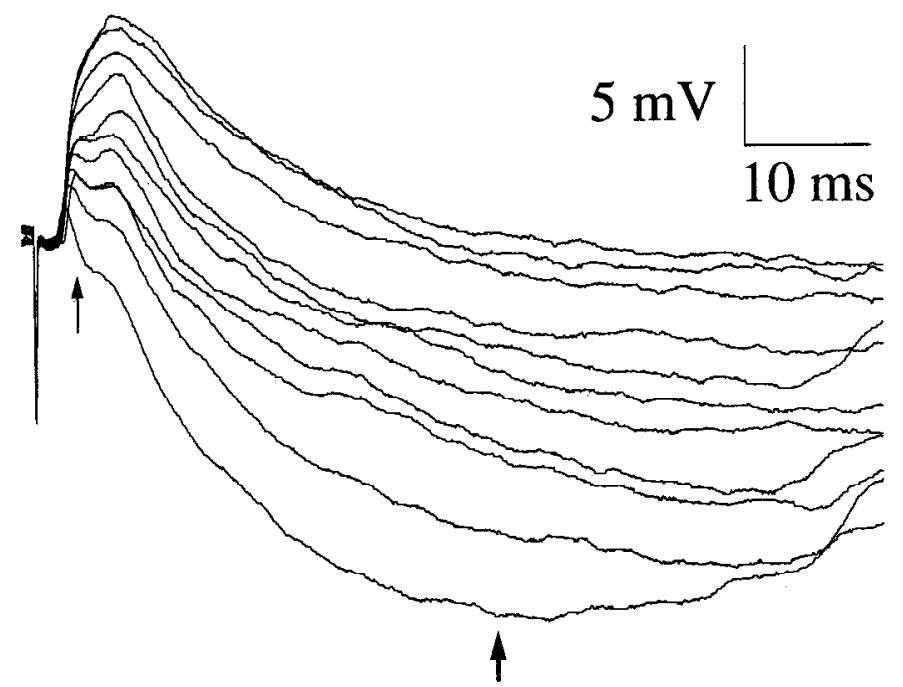

Figure 7. Sample responses to electrical stimulation of the LGN recorded in a second simple cell as a visual stimulus was swept through the receptive field. The thinner arrow points to the peak of the EPSP mediated by monosynaptic excitatory input from geniculate relay cells. This is the point at which the test EPSP amplitude was measured for constructing the plots of Figures 8 and 9. The thicker arrow points to the peak of the IPSP and is the point at which measurements were made for the plots in Figure 12.

more than half as large as the peak amplitude of the preferred response. The response lasted approximately as long as the five phases of the preferred response.

Although Figures 6 and 8 show similar effects, they do so for different components of the test EPSP. In Figure 6, the amplitude of the late EPSP, mediated by corticogeniculate cells, is plotted, while in Figure 8, the amplitude of the early EPSP, mediated by geniculate relay cells, is plotted. The late EPSP component is partially overlapped by the beginning of the disynaptic IPSP (Fig. 5). This could introduce some distortion in the graphs of Figure 6 since the IPSP varies in size during visual stimulation. The distortion is small, however, since the peak of the late EPSP occurs long before the IPSP has grown to its maximum height. For the early component, the distortion is negligible since the EPSP amplitude was measured in Figure 7 at a point at which the IPSP has barely begun, about $1 \mathrm{msec}$ after the EPSP onset.

\section{The relationship between test EPSP size and membrane potential}

The plots of test EPSP size against bar location in Figures 6 and 8 both show that the size of the test EPSP is significantly reduced during some phases of the visual response. In Figure 6 , the reductions occur only in the preferred orientation; in Figure 8, they occur at both stimulus orientations. The common feature of all the plots in Figures 6 and 8 is a direct association not between EPSP size and bar position, but between test EPSP size and membrane potential. Sharp reductions in test EPSP size occurred whenever the membrane was depolarized by the visual stimulus, regardless of its orientation or direction. At the preferred orientation both cells showed significant depolarizations, each of which was accompanied by reductions in test EPSP size. At the null orientation, only one cell showed a significant dcpolarization, and only that cell showed reductions in test EPSP size.
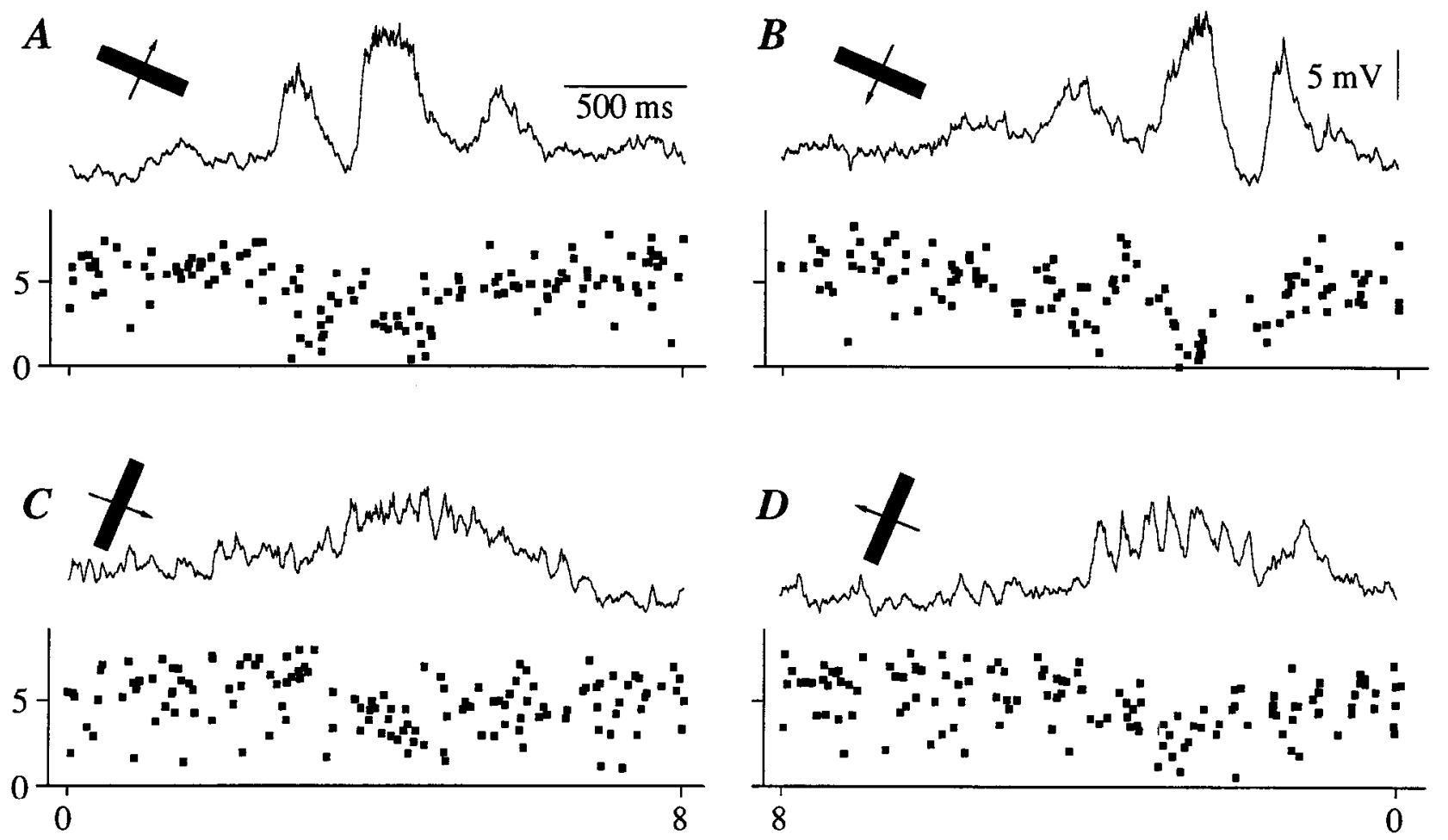

Bar Position (deg)

Figure 8. A plot of test EPSP amplitude against bar position for the cell in Figure 7. In this case component 1 of the test EPSP (the input from geniculate relay cells) has been plotted. The format is identical to that of Figure 6 . The resting potential of this cell was $-60 \mathrm{mV}$. The beginning of each trace, recorded before the visual stimulus enters the receptive field, is near the resting potential. Insets indicate the orientation and direction of the motion of the visual stimulus. 
$\boldsymbol{A}$

\section{Preferred Orientation}

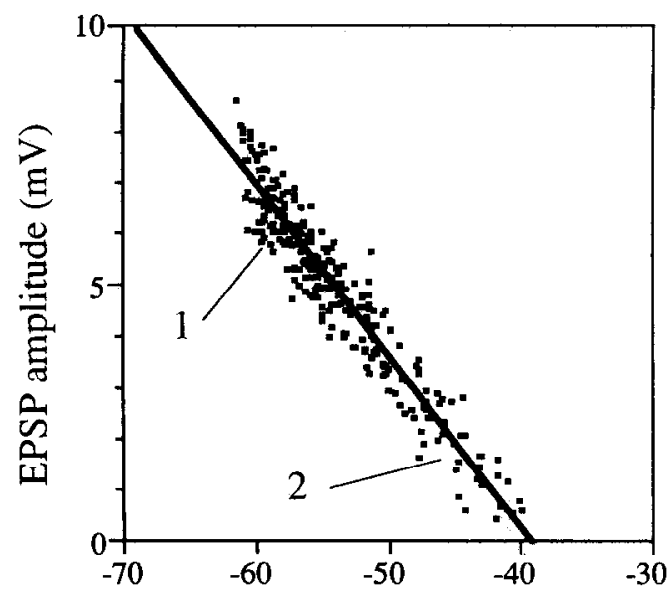

Base Membrane Voltage (mV)

C

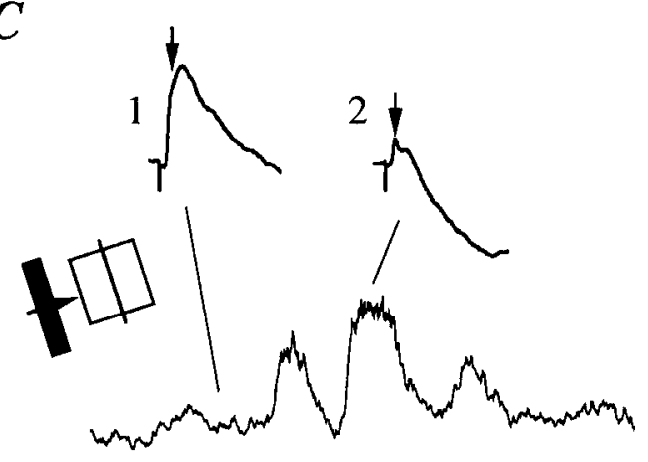

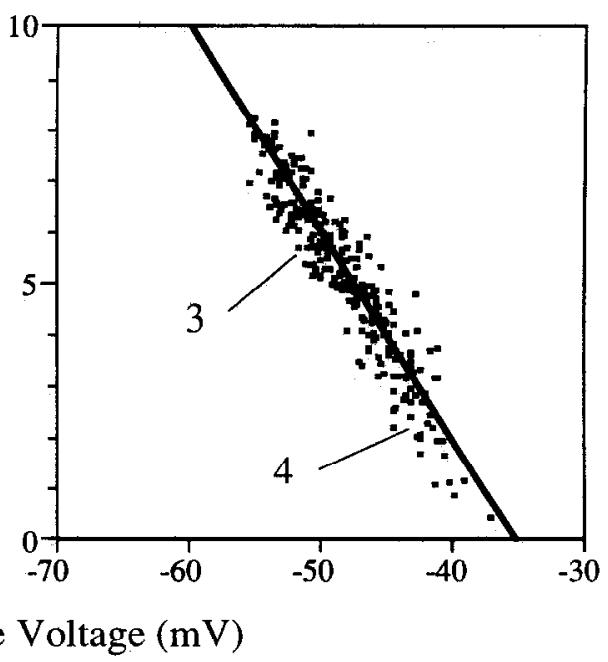

$\boldsymbol{B}$

Null Orientation

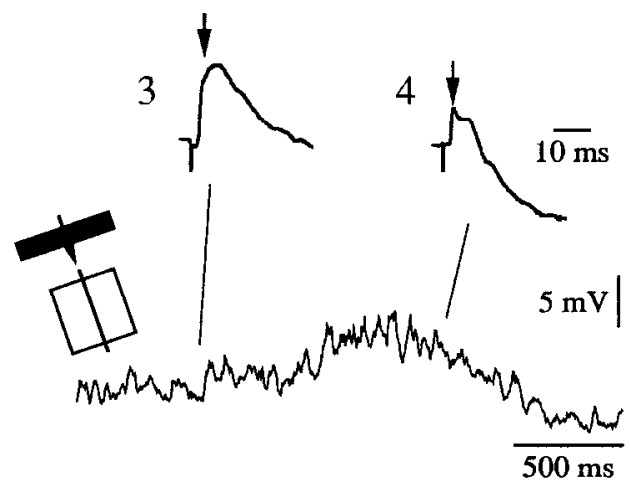

Figure 9. A, A plot of the amplitude of the test EPSP against base membrane potential recorded while the visual stimulus was at the optimal orientation for the cell illustrated in Figure 8. Base potential is the membrane potential measured $1 \mathrm{msec}$ after the shock artifact, just prior to the beginning of the test EPSP. $B$, Test EPSP size versus membrane potential for null orientation. $C$, Average visual response evoked by the same visual stimuli used in $A$ and $B$. Sample traces evoked at different bar positions are shown above the visual trace. Arrows above the traces indicate the point at which the FPSP amplitude was measured. Numbers above the traces correspond to the numbered points in $A$ and $B$.
The exact relationship between the visually cvoked depolarization and test EPSP size is illustrated in Figure 9 for the cell in Figure 8. In Figure 9, $A$ and $B$, the size of each test EPSP is plotted against the base membrane potential (the membrane potential measured $1 \mathrm{msec}$ before the beginning of the test EPSP) for the two orientations of bar motion. The relationship between the test EPSP size and base membrane potential is remarkably linear (Fig. 9A,B). The linear relationship holds for test EPSPs recorded with visual stimulation at either orientation. Furthermore, the graph suggests that test EPSP size is more closely related to base membrane potential than it is to bar position. In Figure 8, at any one bar position the scatter in test EPSP amplitudes is about $4 \mathrm{mV}$, or $50 \%$ of maximum. In Figure 9, $A$ and $B$, at any one membrane potential the scatter in test EPSP amplitudes is about $2 \mathrm{mV}$, or $25 \%$ of maximum. In other words, the changes in test EPSP size may arise directly from changes in base membranc potential. The higher variability associated with bar position may be accounted for by variations in membrane potential that occur from trial to trial at any one bar position.

The similarity between the two graphs of Figure $9 A$ and $B$ provides further evidence that the membrane potential, and not a visually activated inhibitory input, mediates the effect of the visual stimulus on test EPSP size. The relationship between test EPSP size and base membrane potential is nearly identical for the two stimulus orientations; the slopes of the least-squares fits to the two graphs are 0.33 and $0.40(R=0.96$ and 0.94$)$. The lateral shift between the two graphs can be accounted for by a
$5 \mathrm{mV}$ drift in the mcasurcd resting potential between the timc the data for the two graphs were recorded.

Results similar to those shown in Figures 7-9 were obtained from a layer 3 complex cell that received monosynaptic excitation from the LGN. Plots of the size of the electrically evoked monosynaptic EPSP against base membrane potential were as linear as those shown in Figure 9. A membrane depolarization of $25 \mathrm{mV}$ was associated with an $80 \%$ reduction in the size of the test EPSP (from approximately $16 \mathrm{mV}$ to $3 \mathrm{mV}$ ) at both the null and preferred stimulus orientations $(R=0.85$ and 0.82$)$.

The dependence of test EPSP size on base membrane potential can be explained by four possible mechanisms other than shunting inhibition: (1) fatigue of the excitatory synapses, (2) visually evoked changes in activity of the presynaptic axons, (3) reduction of input resistance by the opening of voltage-sensitive channels, and (4) reduction of the driving force on EPSCs (which we will suggest contributes most strongly to Fig. 9). We will consider each of these possibilities in detail in the Discussion.

\section{Hyperpolarizing inhibition}

There is no doubt that substantial hyperpolarizing inhibition is evoked by visual stimulation (Ferster, 1988). The contribution of synaptic inhibition can be measured by comparing the response of a simple cell to visual stimulation in the presence and absence of a steady hyperpolarizing current injected through the recording electrode (Fig. 10). In the figure, the thick lines correspond to responses recorded without current, while the thin lines compared to responses recorded with current. The iniected 


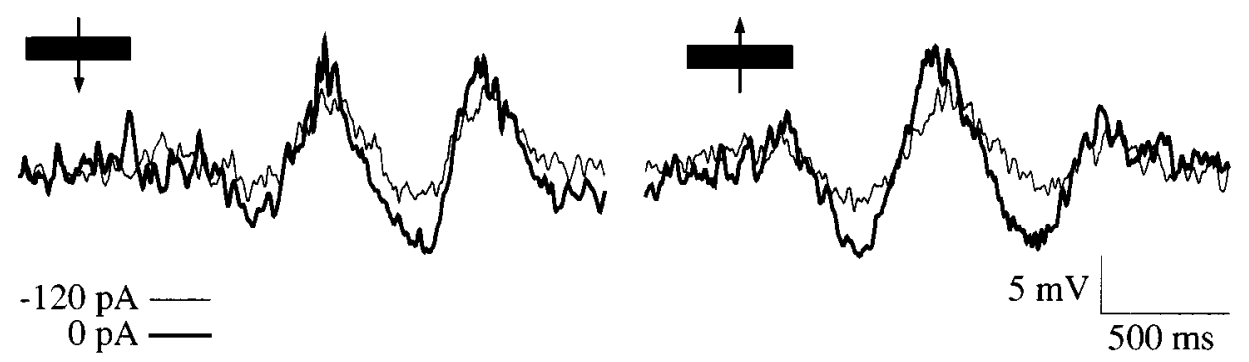

Figure 10. Intracellular responses (of the same neuron illustrated in Fig. 2) to the moving bar stimulus. For each of two directions of motion, the two superimposed traces were recorded with and without a steady hyperpolarizing current $(-120 \mathrm{pA})$ injected through the electrode. The injected current increased the resting potential significantly (approximately $10 \mathrm{mV}$ ), but the traces with and without current are superimposed in order to compare the amplitude of the stimulus-evoked changes in membrane potential. The hyperpolarizing components of the responses are smaller in the presence of hyperpolarizing current, indicating that these hyperpolarizations are in part generated by the activation of inhibitory synapses with a reversal potential below rest. Each trace is an average of four individual responses that was smoothed by a moving boxcar average of 15 msec width.

current, which lowers the membrane potential, decreases the size of the visually evoked hyperpolarizations. This decrease could only occur if the reversal potential of the underlying synaptic events were below the resting membrane potential, that is, if the synapses were inhibitory.

The size of the visually evoked depolarizations is not predicted to be significantly affected by the injected current: because the EPSP driving force is large, current-induced changes in membrane potential have little effect on the size the depolarizations. A $10 \mathrm{mV}$ change in membrane potential caused by the injected current might decrease the IPSP driving force almost to 0 , but increases the EPSP driving force by only $15 \%$. (The visually evoked depolarizations in the traces recorded without current are paradoxically slightly larger that those recorded with current. This is partly the result of the spikes that occur in the absence of current in the individual records making up the averaged traces.)

The visually evoked hyperpolarizations observed in Figures 3 and 10 may also result in part from a reduction in the spontaneous activity of presynaptic excitatory relay cells that underlie the simple cell's receptive field. A significant portion of the hyperpolarizations, however, must result from synaptic inhibition. It has been proposed elsewhere that the inhibition arises from nearby cortical simple cells (Palmer and Davis, 1981; Ferster, 1988).

The biophysical properties of synapses dictate that the size
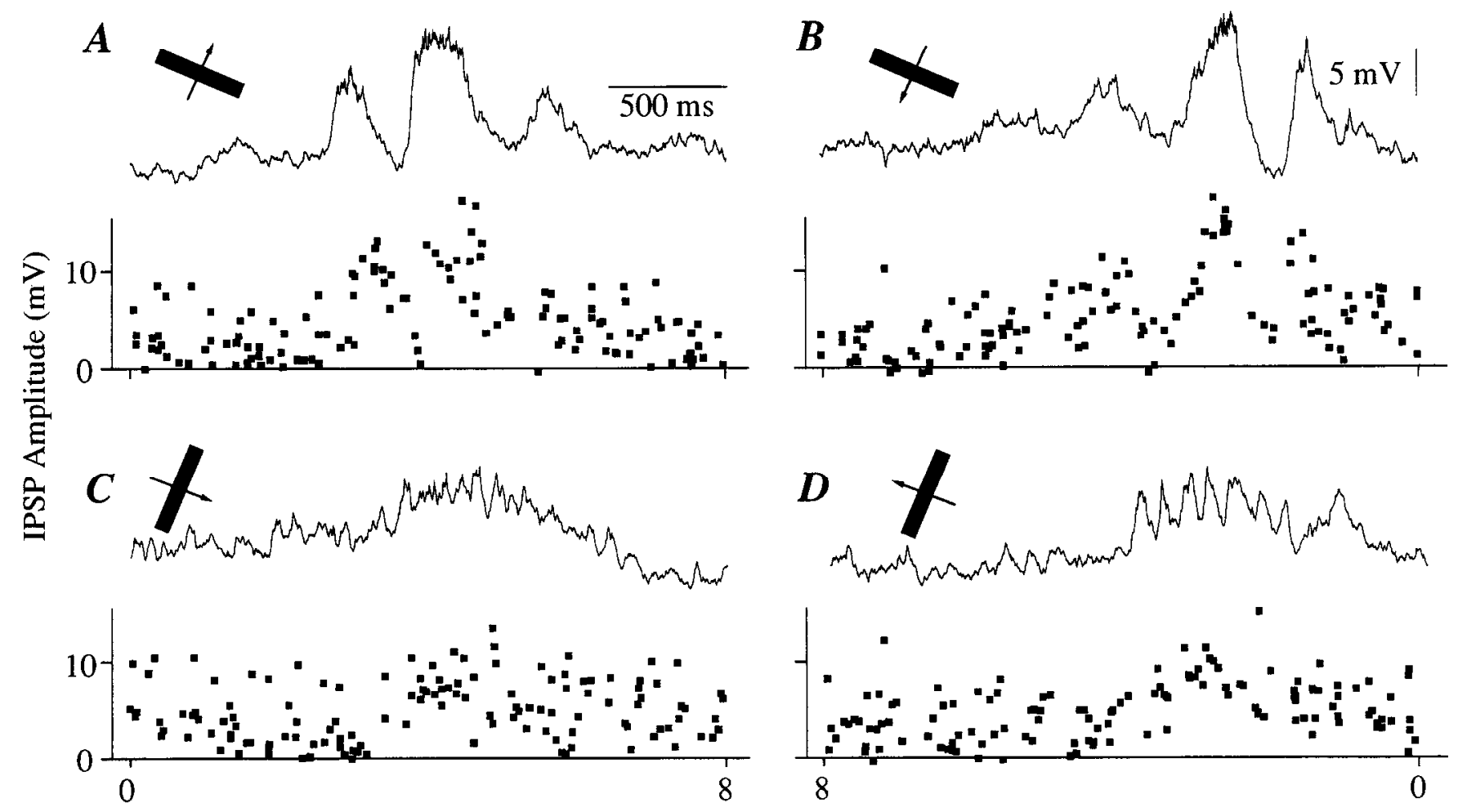

Bar Position (deg)

Figure 11. The response of the simple cell in Figure 8 to the motion of a bar across its receptive field together with a plot of test IPSP size as a function of bar position. Figure format is similar to that of Figures 6 and 8 . Insets indicate the orientation and direction of motion of the visual stimulus. 
$\boldsymbol{A}$

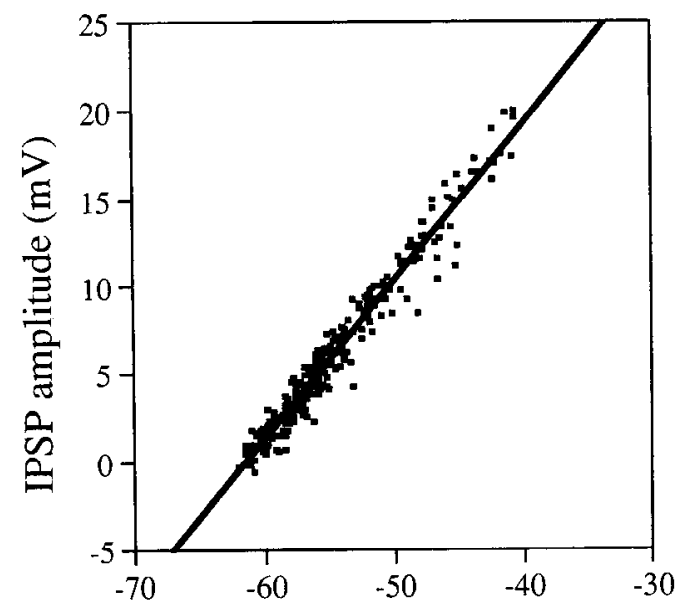

Preferred Orientation
$\boldsymbol{B}$

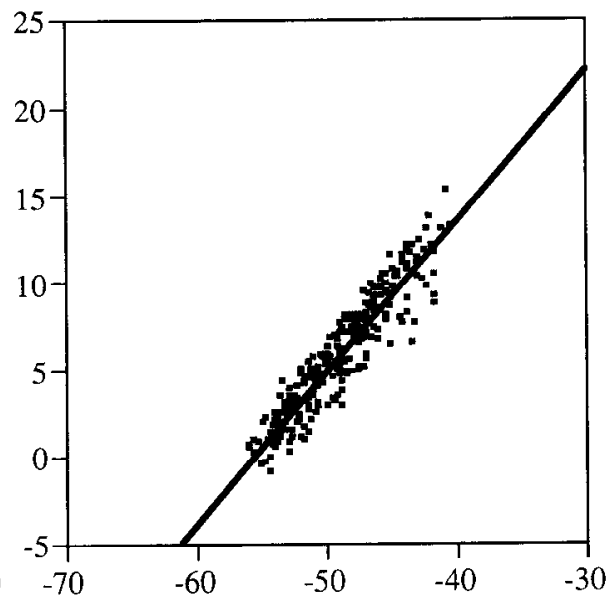

Figure 12. A plot of the amplitude of the test IPSP (measured at a latency of $35 \mathrm{msec}$ ) against base membrane potential for cell illustrated in Figures 8 and 9 . Base potential is the membrane potential measured $1 \mathrm{msec}$ after the shock artifact, just prior to the beginning of the test EPSP.

of an IPSP will be proportional to the difference between membrane potential and IPSP reversal potential. During the response to visual stimulation, then, the larger the visually evoked depolarization, the larger a simultaneously evoked IPSP should be. This is exactly the case in simple cells, as shown by measurements of the size of the electrically evoked IPSP that followed the test EPSP (thick arrow in Fig. 7). Visually evoked changes in test IPSP size and in membrane potential are shown in Figure 11 for the simple cell illustrated in Figures 8 and 9. This cell's response to the moving stimulus showed three distinct depolarizing phases during which the test EPSP decreased in size. The test IPSP did exactly the opposite, increasing in size whenever the membrane was depolarized by the visual stimuli of either orientation. Plots of test IPSP size against base membrane potential for both orientations are shown in Figure 12. As expected, the relationship between IPSP amplitude and membrane potential is linear.

\section{Discussion}

In this experiment, we have failed to find any evidence for shunting inhibition in cells of the cat visual cortex. To search for shunting inhibition, we examined the effects of visual stimulation on the amplitude of a test EPSP evoked by electrical stimulation of the LGN: shunting inhibition, if present, must decrease the size of the test EPSP. Visual stimuli do produce large reductions in the size of the test EPSP, but these reductions are not the result of shunting inhibition. During phases of the visual response in which the membrane is visibly hyperpolarized by IPSPs, the size of the test EPSP is slightly increased (Figs. $6,8)$.

Visually evoked shunting should depend only on the characteristics of the visual stimulus, such as its position, orientation, and direction of motion. The visually evoked changes in test EPSP size are clearly linked with bar position but are much more strongly dependent on membrane potential, including spontaneous fluctuations in membrane potential that occur independently of the visual stimulus (Fig. 9).

The method used to search for shunting inhibition has two strengths. The first is that it directly reveals the end effect of shunting inhibition: the reduction of EPSP size. The second advantage is that the method is sensitive to the presence of shunting inhibition anywhere within the dendritic tree. The synapses activated by the test stimulus are located throughout the dendritic tree (Davis and Sterling, 1979; McGuire et al., 1984; Freund et al., 1985), so that any shunt activated by the visual stimulus will lie near enough to some of the synapses mediating the test EPSP to decrease the test EPSP amplitude. These two aspects of the method make it possible to detect shunting even in portions of the dendritic tree that might be electrotonically remote from the soma.

Shunting synapses evoked by stimuli of the nonpreferred orientation have been proposed as a mechanism for creating or sharpening orientation selectivity of cortical cells (Koch and Poggio, 1985). Douglas et al. (1988) have shown that the input resistance of cortical neurons is not reduced significantly by visual stimulation at the null orientation, suggesting that these stimuli do not activate shunting IPSPs in the soma, or in regions of the dendritic tree closely electrically coupled to the soma. Our experiment demonstrates that visually evoked inhibition does not significantly shunt EPSPs anywhere in the dendritic tree. Visually evoked shunting inhibition would decrease the size of the test EPSP. In thrce of the six cells, significant decreases in test EPSP size were generated by null-oriented stimuli. As illustrated in Figure 9, however, these are not the result of shunting inhibition, but instead arise from visually evoked membrane depolarization. Since the amount of reduction in test EPSP size at each orientation is the same for a given membrane depolarization (compare Fig. $9 A$ and $B$ ), the mechanism underlying the reductions at each orientation is probably the same. Moreover, even if the reduction in test EPSP size in both cases were a result of shunting inhibition, the underlying inhibition cannot sharpen orientation tuning: the reductions in test EPSP size are actually greater at the preferred orientation than at the null.

We note in passing that the results in Figure 9 also provide evidence against the use of presynaptic inhibition at the synapses that mediate the test EPSP. The reasoning that supports this conclusion is analogous to that applied to shunting inhibition. If the visual stimulus were to evoke presynaptic inhibition, test EPSP size would change as a function of bar position and orientation exactly as predicted for shunting inhibition. As we have stated above, the changes in test EPSP size are dependent on depolarization of the postsynaptic cell, not directly on bar po- 
$\boldsymbol{A}$

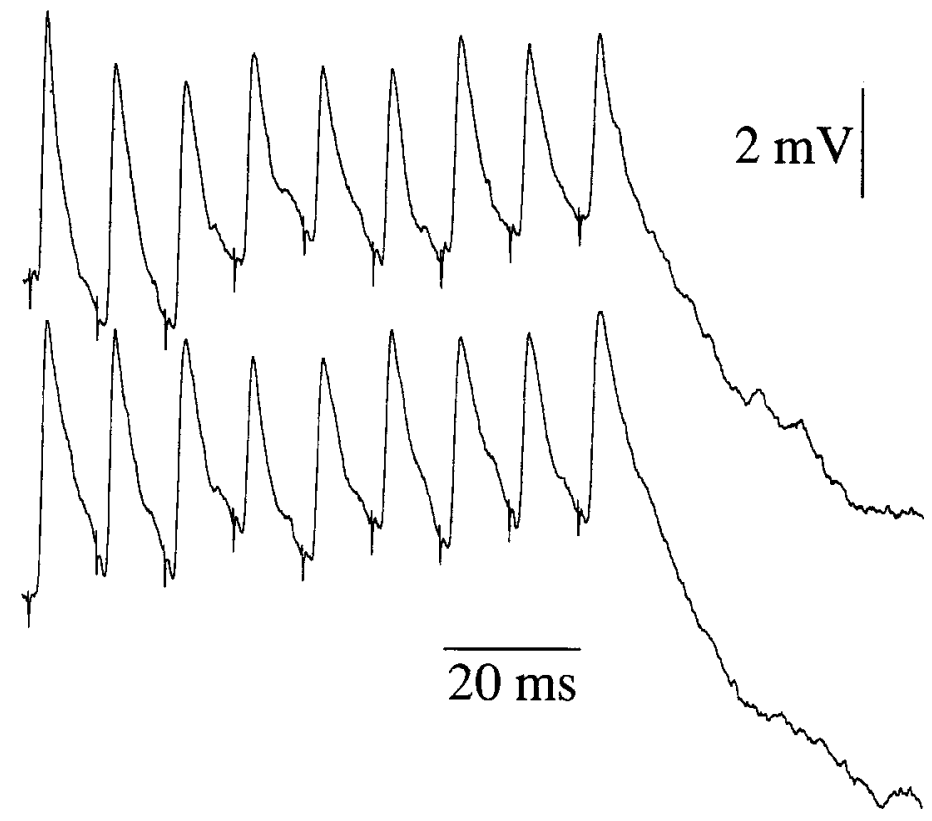

$\boldsymbol{B}$

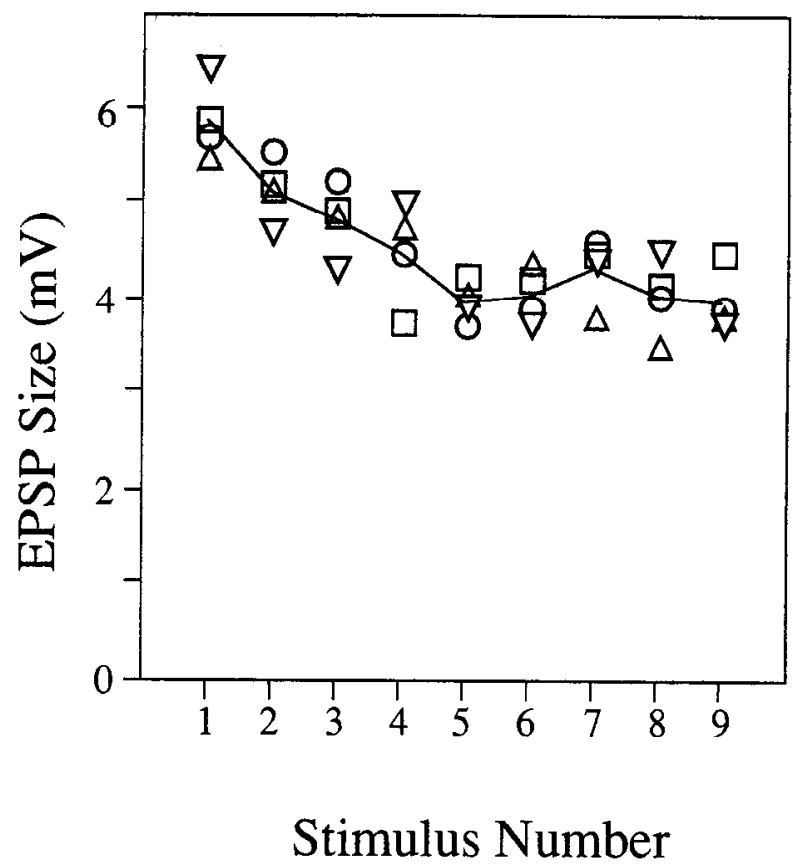

Figure 13. A, The response of a simple ccll to a train of electrical stimuli $(100 \mu \mathrm{A})$ delivered to the LGN. $B, A$ plot of the size of each of the EPSPs evoked by the nine stimuli in the train plotted against stimulus number. Data for the traces illustrated in $A$ and for two other traces are shown. The continuous line represents the average of the four sets of points.

sition. Therefore, presynaptic inhibition cannot explain the observed reductions in EPSP size. This conclusion applies only to synapses mediating components 1 and 2 of the test EPSP. Other excitatory inputs to simple cclls could be subject to presynaptic inhibition, though there is little anatomical evidence for axoaxonic contacts in the visual cortex.

\section{The origin of the linear relationship between test EPSP size and membrane potential}

In the Results, we suggested four possible mechanisms for the visually evoked reductions in test EPSP size that are more likely than shunting inhibition. Here, each will be considered in turn.

(1) Large visually evoked depolarizations require repetitive activation of excitatory synapses, which might cause fatigue in these synapses. Since the visual and electrical stimuli activate many of the same presynaptic neurons (geniculate relay cells and corticothalamic cells), visually induced fatigue could cause the reductions in test EPSP size observed in Figure 9. To measure the extent of the fatigue that occurs in geniculocortical synapses, we electrically stimulated the LGN at $100 \mathrm{~Hz}$ and recorded the EPSPs evoked in a layer 4 simple cell (Fig. 13A). The traces show that there is a small but noticeable decrease in EPSP size during the course of the stimulus train. When the average EPSP size for four traces is plotted against stimulus number (Fig. 13B, solid line), a $25-30 \%$ reduction in EPSP size can be seen.

It should be noted that the fatigue mechanism affects only those presynaptic neurons activated simultaneously by the visual stimulus and the electrical stimulus. The electrical stimulus is supramaximal and presumably activates nearly all the axons presynaptic to the simple cell. The visual stimulus activates at any one time only those geniculate neurons contributing to one or two subfields in one eye. Fatigue will therefore affect only a fraction of the electrically activated axons and is unlikely to explain completely the large effects of visual stimulation on test EPSP size.

(2) Changes in the presynaptic volley might occur if the test EPSP were disynaptic. Visual stimulation could then reduce the excitability of the interneurons mediating the test EPSP, which would, in turn, result in a reduction in test EPSP size. In the test EPSP of Figures $5 A$ and 7, however, both components are monosynaptic (though component 1 is orthodromically activated and component 2 is antidromically activated). Therefore, changes in the presynaptic volley caused by changes in the excitability of interneurons cannot explain the relationship shown in Figure 9.

The visual stimulus might also affect the presynaptic volley through collision between visually and electrically evoked spikes in the presynaptic axons. During a visually evoked depolarization, the number of geniculate relay cells firing at any given time increases, thus increasing the percentage of axons that are in their refractory period when the electrical stimulus is delivered. The sizc of the test EPSP would consequently be reduced because fewer axons would respond to the electrical stimulus. The reduction would be significant if the visually evoked firing rates in a large number of geniculate neurons were to approach the maximum firing rate that their axons can sustain. Geniculate neurons can easily fire at rates as high as $200 \mathrm{~Hz}$ in response to high-contrast stimuli of the type used here (Cleland and Lee, 1985). As with fatigue, however, the collision mechanism will affect only those axons that are visually active, which is likely to be only a fraction of those activated by the electrical stimulus.

(3) The visually evoked depolarization likely opens voltagesensitive ion channels that are known to be present in most neurons of the mammalian CNS. If the conductance of these channels is large enough, they could reduce the cell's input re- 
sistance, which would in turn reduce the size of the test EPSP. Tests with injected current pulses indicate that the input resistance of some cortical cells is reduced by no more than $20 \%$ by visual stimuli (Berman et al., 1991). Figure 12 confirms this observation.

The evidence depends on the fact that the size of the test IPSP depends not only on base membrane potential, but on input resistance as wcll. By Ohm's law, the inhibitory postsynaptic current (IPSC) that flows through $g_{\text {syn }}$, the synaptic conductance, produces a voltage proportional to $R_{\text {in }}$, the cell's input resistance. For $g_{\text {syn }} \ll 1 / R_{\text {in }}$

$$
\begin{aligned}
& \Delta V_{\text {syn }}=\operatorname{IPSC} \cdot R_{\text {in }}, \\
& \text { IPSC }=\left(V_{m}-E_{\text {rev }}\right) \cdot g_{\text {syn }}, \\
& \Delta V_{\text {syn }}=\left(V_{m}-E_{\text {rev }}\right) \cdot g_{\text {syn }} \cdot R_{\text {in }} .
\end{aligned}
$$

Assuming that $g_{\text {syn }}$ is constant from trial to trial, the test IPSC can be used to monitor input resistance, as could be done with a small current pulse injected through the recording electrode. The test IPSC cannot measure absolute input resistance, however, since the conductance change, $g_{\text {syn }}$, is unknown; only variations in input resistance can be detected. However, the IPSC, unlike the current pulse, measures the input resistance not at the soma, but at the site of the inhibitory synapses, wherever they are in the dendritic tree. The linear relationship of Figure 12 suggests that except perhaps at or above the threshold, the cell's input resistance does not change during the visual response, even when the cell is significantly depolarized. This question may best be addressed in the future with voltage-clamp experiments.

(4) The mechanism that we feel most likely explains the visually evoked reduction in test EPSP size is that visually cvoked depolarizations reduce the driving force on EPSCs activated by the test stimulus. The known properties of postsynaptic currents, as summarized in Equation 1, predict the linear relationship shown in Figure 9. Assuming, for example, a reversal potential of $0 \mathrm{mV}$ for the test EPSP (Coombs et al., 1955; Finkel and Redman, 1983; Jahr and Stevens, 1987; Yakel et al., 1988), at the $-60 \mathrm{mV}$ resting potential of this cell, the electrochemical driving force on the EPSC would be $60 \mathrm{mV}$. In the presence of a visually evoked depolarization of $10 \mathrm{mV}$ at the site of the excitatory synapses, the driving force would then be reduced by one-sixth, from $60 \mathrm{mV}$ to $50 \mathrm{mV}$. Consequently, the EPSC and EPSP will be reduced by one-sixth. The reduction in test EPSP size associated with a $10 \mathrm{mV}$ depolarization in Figure 9 is surprisingly much larger than one-sixth, about $50 \%$. In order for this large change in test EPSP size to be explained in terms of a reduction of ionic driving force, the visually evoked change in membrane potential at the site of the excitatory synapses must be three to four times larger than that seen in the cell body.

\section{Evidence that depolarizations in the dendrites are larger than those seen at the soma}

Further evidence that visually evoked depolarizations are larger in the dendrites than in the soma arises from a peculiar feature of the responses shown in Figure 6. In Figure $6 A$, the first depolarization (phase 2) in the response represents the entry of the bar into $\mathrm{ON}$ region 2, while the second (phase 4) represents the exit from OFF region 3 . The first depolarization likely reflects activity in presynaptic ON-center cells, and the second reflects presynaptic activity in OFF-center cells. In Figure $6 B$, as the bar passes in the other direction across the receptive field, it enters $O N$ region 2 and leaves the OFF region 3 simultaneously. The same ON- and OFF-center cells that in Figure $6 \mathrm{~A}$ were activated sequentially are now activated simultaneously. The presynaptic activity now equals the sum of the presynaptic activity that underlies the two depolarizations in Figure $6 \mathrm{~A}$. One would expect, therefore, that the depolarization in Figure $6 B$ should equal the sum of the two depolarizations in $A$. Surprisingly, it does not; as the bar moves from the OFF rcgion to the $\mathrm{ON}$ region (phase 2 in Fig. $6 B$ ), the depolarization is no larger than either phase 2 or 4 in $A$.

This nonlinear interaction between the ON and OFF excitatory inputs cannot be explained by fatigue of synapses or collision of action potentials; two completely independent sets of inputs are activated simultaneously as the bar passes from the OFF region to the ON region in Figure $6 B$. The nonlinear interaction between $\mathrm{ON}$ and OFF inputs can most easily be explained by assuming that the depolarization in the dendrites is far larger than that observed in the cell body. In that case, the depolarization from the ON input would by itself bring the membrane potential of the dendrites close to the EPSP reversal potential. Active processes, such as dendritic voltage-activated $\mathrm{Ca}^{2+}$ channels, could assist the synaptic input in driving the membrane potential to the EPSP reversal potential. In any case, additional input from OFF-center cells would have little further effect on the membrane potential because the driving force on EPSCs is now so small. Assuming a reversal potential for EPSPs near $0 \mathrm{mV}$, the depolarization in the dendrites of this cell would have to be three to four times as large as that measured in cell body. This mechanism would fully explain the substantial drop in test EPSP size associated with visually evoked depolarizations observed in Figure 6.

\section{The electrotonic properties of simple cell dendrites}

Surprisingly, the relationship expressed in the graphs of Figure 9 give an indirect measure of the electrotonic properties of simple cell dendrites and spines. We have proposed that reductions in test EPSP size arise from depolarization-induced reductions in the EPSC driving force. Given this assumption, visually evoked depolarizations of $15 \mathrm{mV}$ in the soma are only $25-30 \%$ of the $50-60 \mathrm{mV}$ depolarization present at the excitatory synapse. A $25-30 \%$ decrement corresponds to an attenuation of slightly more than $1 / e$, implying that the synapses mediating both early and late components of the test EPSP lie about 1 dendritic length constant away from the soma.

At first it might seem inefficient to decouple dendritic synapses electrically from the soma to the extent observed. Why should excitatory synapses depolarize the nearby membrane by $60 \mathrm{mV}$, only to have $75 \%$ of the depolarization decay away by the time it reaches the soma? An advantage of the attenuation between dendrite and soma is that it maps the full dynamic range of the excitatory synapses, the $60 \mathrm{mV}$ between rest and the reversal potential, onto the full dynamic range of the spikegenerating mechanism, the $15 \mathrm{mV}$ between rest and the spike threshold (Koch and Poggio, 1983). In this way, the synapses can control the generation of spikes with fourfold greater resolution than they could have without the attenuation.

A similar attenuation may occur between the dendrites and soma in motoneurons of the cat. Iansek and Redman (1973) measured the passive electrical properties of motoneuron dendrites by measuring the response to brief current pulses and found the length constants of dendrites to be one to two times their physical lengths. 


\section{Synaptic integration in simple cells}

Two features make shunting inhibition an attractive mechanism for neuronal modeling. The first is that the interaction between excitation and shunting inhibition is nonlinear-the size of EPSPs is divided by the size of the shunting conductance. The nonlinear interaction allows for the implementation of the AND-NOT gate, or the synaptic veto mechanism by single cells (Koch et al., 1983). The AND-NOT gate has proven useful in modeling the origin of complex receptive field properties such as direction, orientation, and disparity selectivity (Koch and Poggio, 1985). The second important feature of shunting inhibition is its restricted site of action. Shunting synapses act locally within the dendritic tree because they generate no synaptic currents. Instead, their conductances act as a passive sink for excitatory current generated within a restricted region of the dendritic tree. Since each region can operate independently as a separate computational unit, a single neuron would be able to perform multiple parallel operations on separate sets of synaptic inputs located within different regions of the dendritic tree. The soma would then integrate the results of these individual operations.

The picture of a neuron that emerges from the test EPSP experiment is a much simpler one. Inhibitory synapses do not act silently through an increase in membrane conductance, but instead actively hyperpolarize the membrane away from the spike threshold by injecting negative current. The interaction bctwcen inhibition and excitation is linear-EPSPs and IPSPs sum to produce a net change in membrane potential. In addition, the dendritic tree acts as a single computational unit, rather than as a set of independent units: hyperpolarizing IPSPs do not act locally but spread to the soma where they interact with synaptic potentials arriving from all over the dendritic tree. EPSPs and IPSPs add linearly at the soma according to simple circuit principles, which form the foundations for the creation of intricate receptive field properties.

\section{References}

Berman NJ, Douglas RJ, Martin KAC, Whitteridge D (1991) Mechanisms of inhibition in cat visual cortex. J Physiol (Lond) 440:697722.

Blanton MG, Lo Turco JJ, Kriegstein AR (1989) Whole cell recording from neurons in slices of reptilian and mammalian cerebral cortex. J Neurosci Methods 30:203-210.

Blomfield S (1974) Arithmetical operations performed by nerve cells. Brain Res 69:115-124.

Chapman B, Zahs KR, Stryker MP (1991) Relation of cortical cell orientation sclectivity to alignment of receptive fields of the geniculocortical afferents that arborize within a single orientation column in the ferret visual cortex. J Neurosci 11:1347-1358.

Cleland BG, Lee BB (1985) A comparison of visual responses of cat lateral geniculate nucleus neurones with those of ganglion cells afferent to them. J Physiol (Lond) 369:249-268.

Coombs JS, Eccles JC, Fatt P (1955) Excitatory synaptic action in motoneurones. J Physiol (Lond) 130:374-395.

Davis TL, Sterling P (1979) Microcircuitry of cat visual cortex: classification of neurons in layer IV of area 17, and identification of patterns of lateral geniculate input. J Comp Neurol 188:599-628.

Douglas RJ, Martin KAC, Whitteridge D (1988) Selective responses of visual cortical cells do not depend on shunting inhibition. Nature 332:642-644.

Eccles JC (1961) The naturc of central inhibition. Proc R Soc Lond [Biol] 153:445-476.
Edwards FR, Hirst GDS, Silinsky EM (1976) Interaction between inhibitory and excitatory synaptic potentials at a peripheral neurone. J Physiol (Lond) 259:647-663.

Fatt P, Katz B (1953) The effect of inhibitory nerve impulses on a crustacean muscle fiber. J Physiol (Lond) 121:374-389.

Ferster D (1981) A comparison of binocular depth mechanisms in areas 17 and 18 of the cat visual cortex. J Physiol (Lond) 311:623655.

Ferster D (1988) Spatially opponent excitation and inhibition in simple cells of the cat visual cortex. J Neurosci 8:1172-1 180.

Ferster D, Lindström S (1983) An intracellular analysis of geniculocortical connectivity in area 17 of the cat. J Physiol (Lond) 342:181215.

Ferster D, Lindström S (1985) Synaptic excitation of neurones in area 17 of the cat by intracortical axon collaterals of cortico-geniculate cells. J Physiol (Lond) 367:233-252.

Finkel AS, Redman SJ (1983) The synaptic current evoked in cat spinal motoneurones by impulses in single group la axons. J Physiol (Lond) 342:61 5-632.

Freund TF, Martin KAC, Somogyi P, Whitteridge D (1985) Innervation of cat visual areas 17 and 18 by physiologically identified $X$ and $Y$-type thalamic afferents. II. Identification of postsynaptic targets by GABA immunocytochemistry and Golgi impregnation. J Comp Neurol 242:275-291.

Hamill OP, Marty A, Neher E, Sakmann B, Sigworth FJ (1981) Improved patch-clamp techniques for high-resolution current recording from cells and cell-free membrane patches. Pflügers Arch 391:85100 .

Hubel DH, Wiesel TN (1962) Receptive fields, hinocular interaction and functional architecture in the cat's visual cortex. J Physiol (Lond) 160:106-154.

Iansck R, Redman SJ (1973) $\Lambda \mathrm{n}$ analysis of the cable properties of spinal motoneurones using a brief intracellular current pulse. J Physiol (Lond) 234:613-636.

Jahr CE, Stevens CF (1987) Giutamate activates multiple single channel conductances in hippocampal neurons. Nature 325:522-525.

Koch C, Poggio T (1983) A theoretical analysis of electrical properties of spines. Proc R Soc Lond [Biol] 218:455-477.

Koch C, Poggio T (1985) The synaptic veto mechanism: does it underlie direction and orientation selectivity in the visual cortex. Models of the visual cortex (Rose D, Dobson VG, eds), pp 408-419. New York: Wiley.

Koch C, Poggio T, Torre V (1982) Retinal ganglion cells: a functional interpretation of dendritic morphology. Philos Trans R Soc Lond [Biol] 298:227-264.

Koch C, Poggio T, Torre V (1983) Nonlinear interactions in a dendritic tree: localization, timing, and role in information processing. Proc Natl Acad Sci USA 80:2799-2802.

Koch C, Douglas R, Wehmeier U (1990) Visibility of synaptically induced conductance changes: theory and simulations of anatomically characterized cortical pyramidal cells. J Neurosci 10:1728-1744.

McGuire BA, Hornung J-P, Gilbert CD, Wiesel TN (1984) Patterns of synaptic input to layer 4 of the cat striate cortex. J Neurosci 4: 3021-3033.

Palmer LA, Davis TL (1981) Comparison of responses to moving and stationary stimuli in cat striate cortex. J Neurophysiol 46:277-295.

Pei X, Volgushey M, Vidyasagar TR, Creutzfeldt OD (1991) Whole cell recording and conductance measurements in cat visual cortex in vivo. NeuroReports 2:485-488.

Rumelhart DE, McClelland JL (1986) Parallel distributed processing: explorations in the microstructure of cognition. Cambridge, MA: MIT Press.

Torre V, Poggio T (1978) A synaptic mechanism possibly underlying directional selectivity to motion. Proc R Soc Lond [Biol] 202:409416.

Yakel JL, Trussel LO, Jackson MB (1988) Three serotonin responses in cultured mouse hippocampal and striatal neurons. J Neurosci 8: $1273-1285$ 